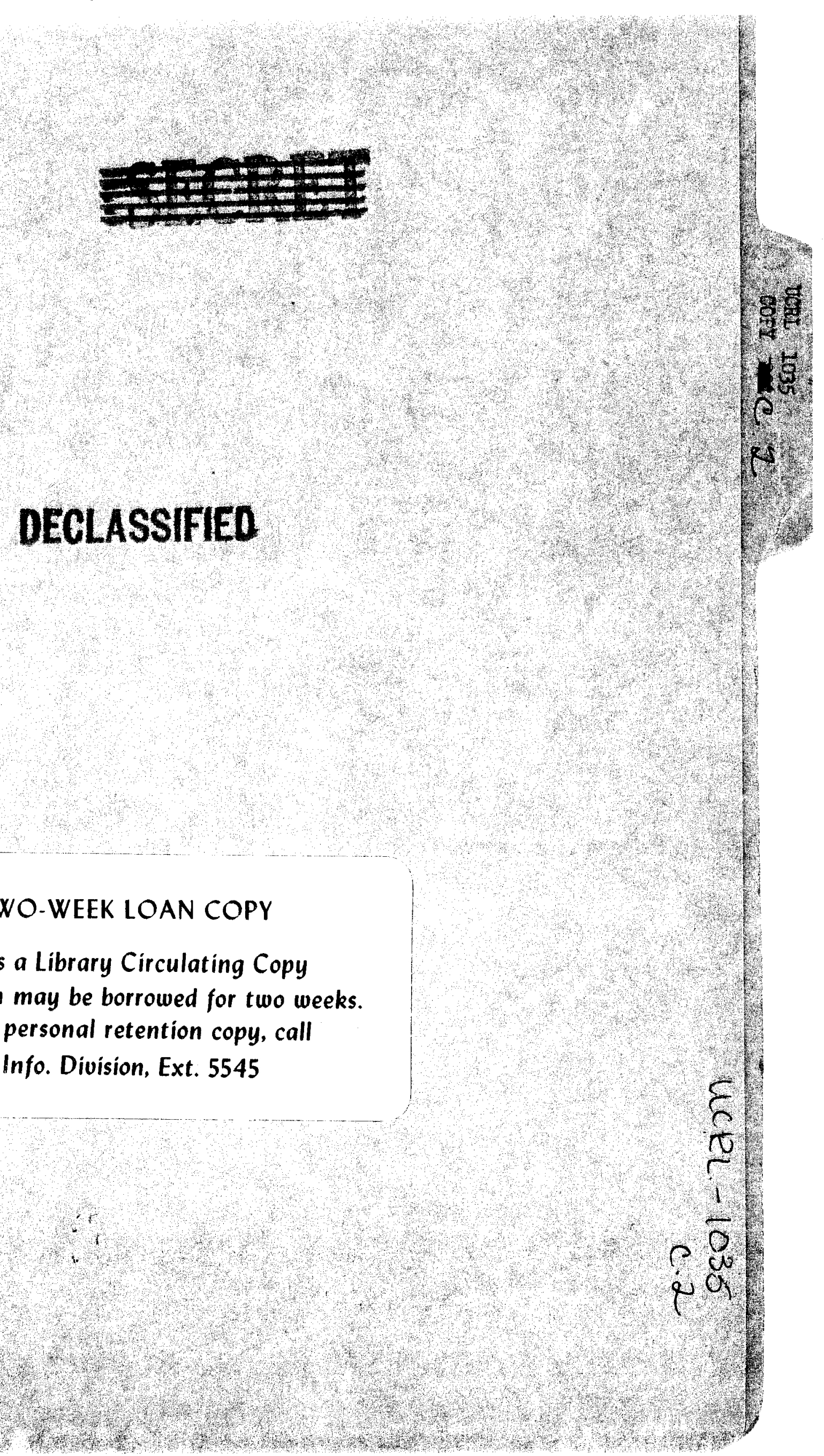


UNIVERSITY OF CALIFORNIA Radiation Laboratory
Cover Sheet

Do not remove
INDEX NO. UCRL-1035

This document contains 6 pages

This is copy 23 of 26 Series $A$

\section{DECLASSIFIED ssued to Into. Div. UCRL $_{\text {U. }}$}

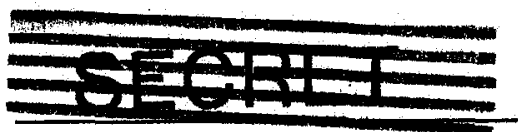

Classification

Each person who receives this document must sign the cover sheet in the space below

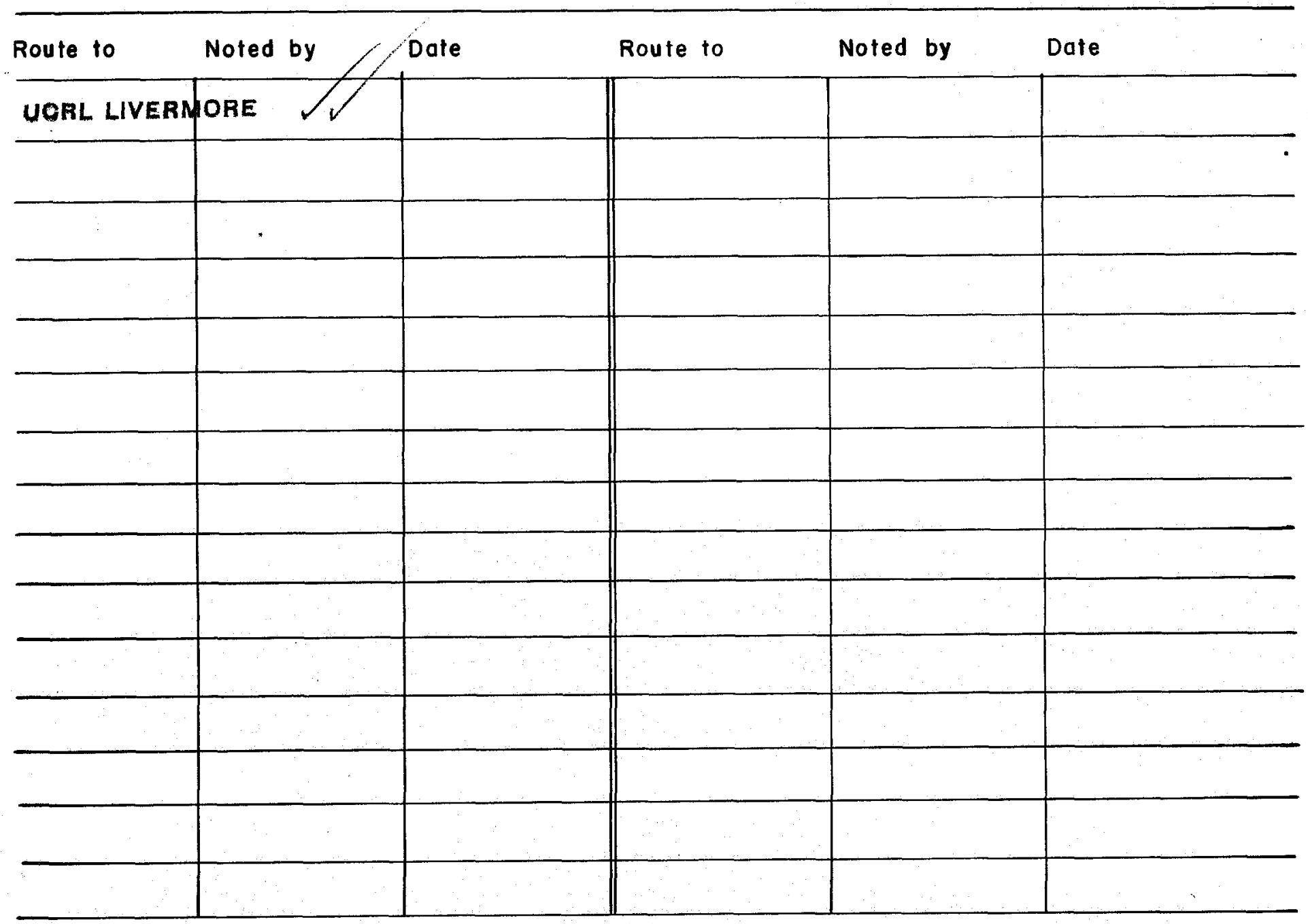


UNIVERSITY OF CALIFORNIA RADIATION LABORATORY

Contract No. W-7405-eng-48

\section{RESTRICTED DATA}

This document contains restricted date as defined in the Atomic Energy Act of 1940. Its transmittal or the disclosure of its contents in any monner to an unawtharized person is prohibited.

CALIFORNIA RESEARCH \& DEVELOPMENT COMPANY

Contract No. AT(1l-1)-74

\section{DECLASSIFIED}

MINUTES OF MTA PROGRESS MEETING

HEID DECEMBER 5, 1950

Russell H. Ball

Berkeley, California

CLASSIFICATION CANCELLED

BY AUTHORITY OF THE DECLASSIFICATION $\underset{\substack{\text { SIGNATURE OF THE } \\ \text { PERSON MAKING THE }}}{\text { CHANYH USAEC }} \frac{4-5-57}{\text { DATE }}$ 
Atomi Energy Commission, Washington

Oak Ridge National Laboratory, $X-10$ Site

Oak Ridge National Laboratory, Y-12 Site

Patent Branoh, Washington

Technical Information Serviee, Oak Ridge

University of California Radiation Laboratory

$8-12$

$13-26$

RESEARCH SERVICE BRANCH

Atomic Bnergy Commission

Berkeley Area

Berkeley, California

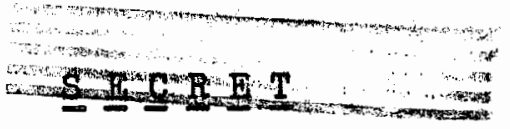




\title{
MINUTES OF MTA PROGRESS MEETING \\ HELL DECEMBER 5, 1950
}

\begin{abstract}
Present: UCRL: Baker, Brobeck, Brown, Cork, Farly, Gordon, Hanson, Judd, Kilpatrick, Latimer, Lawrenee, Lofgren, Longacre, Martin, Martinelli, MoMillan, Norton, Panofsky, Reynolds, Serber, Sewell, Twitchell, Van Atta, Wallace

CRDC: Chaffe, Cope, Crandall, Hansen, Hildebrand, Maker, Powell, Waithman

AEC: Ball, Killough

Los Alamos: John Wheeler
\end{abstract}

Baker said they have 4 bias probes in the bottom of the B-l cavity to aot as de-ionizers in the hope that they would oiroumvent ion locking, but they have not yet show any beneficial effect. They may possibly be placed in the wrong locations. It is observed that the region above the sphere de-ionizes first。 When voltage is put on the probes the lower region also clears but glow discharge can still be seen in the central region of the cavity.

Baker said a means has been devised to overcome the ion looking problem in the B-I test eavity. This is accomplished with the system diagrammed in Figure 1.

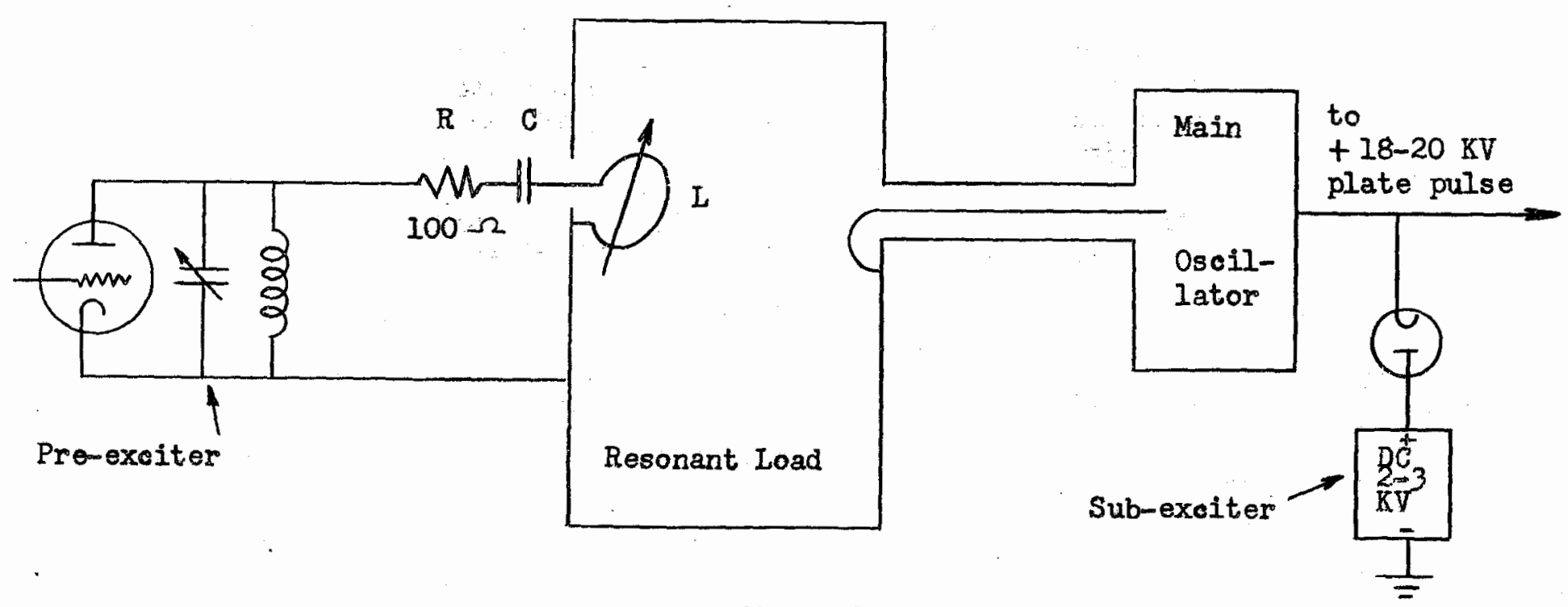

Figure 1 
The pre-exeiter is an ordinary Hartley type self-excited oscillator that will ocme up to full power in 1-2 mioroseconds after a voltage pulse is applied to the plate. This oscillat or will work into a load of about 100 ohms. The capaeity of the condenser $C$ is chosen so that at the resonant frequency of the load $\mathrm{X}_{\mathrm{C}} \approx \mathrm{X}_{\mathrm{I}}$ where $\mathrm{X}_{\mathrm{L}}$ is the inductire reactance due to the coupling $100 \mathrm{p}_{0}$ Under this condition the pre-exciter is feeding into a pure resistive load. There will thus be no net reactance reflected back to the pre-exciter and consequently there will be no tendenoy for the osoillator frequency to shift. If the frequeney of the pre-exciter is adjusted to resonant frequency of the cavity as mugh as 100 amps of $\mathrm{RF}$ current can be supplied through the resistance to the coupling loop. With the appearance of a back emf at the coupling loop the oscillator and cavity lock together and the power buildup becomes very rapid. Breaking through the ion locking region requires a minimum build up time of 100 mieroseconds. Ion locking occurs at $150 \mathrm{KV}$ on the sphere of the resonant load at a pressure of $0.05 \mu$ amps. Onoe sufficient $R F$ voltage appears in the load operation can be maintained by the main oscillator provided the voltage gradient in the load is not permitted to fall below the value at which ion looking occurs. This is prevented by the sub-exoiter which maintains a

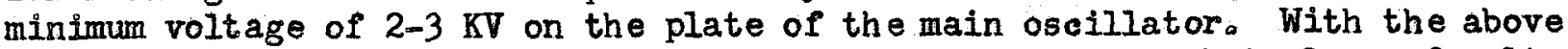
arrangement the pre-exciter will be required only after complete loss of voltage in the avity such as will accompany sparking.

The pre-exciter has a coupling $100 p_{8}$ the area of which can be varied up to a maximum of about three square feet. A loop of large area is used in order to supply the pro-exeiter with suffieient "leverage" to break through the ion looking region. If this large loop remains in the tank after pro-exoitation has been achieved one will have either to insulate against the high voltage (ea $100 \mathrm{KV}$ ) induced in the loop by the full intensity $\mathrm{B}-\mathrm{M}$ field in the cavity or to provide for means of shorting out the intense currents indueed in the loop if it is shorted out.

Panofiky suggested using a TR box to short out the coupling loop and thus eliminate the neessity of providing for removal of the loop after preexoitation, which would otherwise be required since insulation of the preexciter from the indued voltage of about $100 \mathrm{KV}$ is not practioal.

The next limitation on the power level for the B-l cavity will be the X-ray intensity. It is not known how severe the $X$-ray problem will be, but at the present voltage of $1,000,000$ volts in the cavity the X-ray level is rather high. The X-ray production may largely be due to the presenee of dust in the eavity sinee prolonged operation, espeoially sparking, appears to noticeably reduee the X-ray level of the cavity.

Longacre said the electron model of Mark I has been running wello In order to overcome multipactoring they have been using extra bias on the dirft tubes and higher ourrent in the focusing magnets than is required to model the operation of Mark Io The phase acceptanee angle under these conditions is greater than 1800 due to the bias present on the first drift tube which effectively produses a DC lens in the first gap. This shows that one can achieve rf acceleration with a large phase acoeptanoe angle and obtain a monoenergetio beam 
of very small diameter. Extrapolation of this beam to full-seale gives a 5-inch diameter at half intensity at a distance of 20 feet from the end of the accelerator. These figures are somewhat qualitative since present operation is not under scaled conditions. Panofsky said that plaoing of electrodes around the midpoints of the gaps to eliminate multipactoring would probably do no good sinee the diameter of the drift tubes is large compared to the gap spacing so that there would be little field penetration into the gap where the multipactoring occurs. The foousing magnets are now being run at 4 times their rated ourrento

Sewell said that on the electron model of the eyclotron they can accelerate to $70 \mathrm{Kew}$ which models the relativistio behavior of deuterons up to an energy of $250 \mathrm{Mer}$ and that they are now interested in determining the maximum currents that can be obtained. It has therefore been proposed to convert the XC magnet to a Thomas-type eyelotron for prot on acceleration. Protons have been chosen rather than deuterons since they can be acoelerated with this small mashine to: a higher beta and it is the beta which determines the contour of the pole faces. When converted, the XC eyclotron is expected to give protons between 20 and $30 \mathrm{Mev}$ which corresponds to a beta of about 0.2. This proton eyelotron will be required for accurate determination of heavy particle beam eurrents attainable sinoe this information cannot be obtained from an electron-acoelerating model. The machine will be pulsed in order to minimize the radiation hazard and to redue the requirements for the power supply. Due to the odd shape of the pole base of the XC magnet considerable shimming of the magnet faces will be required. The "hills" of the pole faces will be built up of quarter-inch and half-inch steel plates. It is hoped to have this ayolotron in operation in April 1951.

Hansen sald that $I 1$ of the support rings are in place at livermore。 The 12th is being assembled on the ground. The 14th ring has been returned to the shop due to a poor welding job. The steel erection is about $35 \%$ complete. The east-west tunnel on the south side of the building has its slab poured and the side walls and top are being poured this week. The building steel has been shipped from Los Angeles and it is hoped that erection of this steel can begin the first of next week. Thomas and Rosendahl have the pipe fabrication well allong. They will probably start assembling the cavity about the 15th of December. The foundation slab for the power supply building will be poured today. The contract with Oscar Krenz for fabrioation of the liner has been pretty well worked out. They are now working with Oscar Krenz to suggest methods of doing the work and assisting them in a search for more shop area either in Livermore or scme place in Berkeley. A determination of where this work can be done depends upon final methods ohosen for fabrioation. There are some furnaes available in Berkeley but they may not be large enough to accommodate a full liner section so as to allow a simultaneous soldering of the full compliment of the cooling tubes to each section. They are working on the idea of a chain torch to solder all the tubes in one pass. Bids have been received on the transmission lines. Berkeley steel Construction Company is the low bidder, with a bid of about $\$ 60,000$. Since they are not well pleased with some of this company's past work they will have to utilize a rigid inspeation system if this contractor is chosen. The contract has been let for the

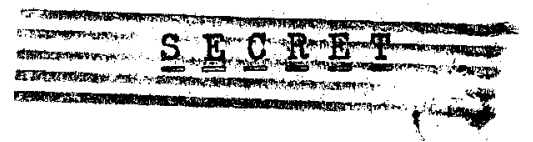


7ofoot shielding blooks。: Hildebrand said that CR\&D and UCRL have decided on the specifications for the IrI test cavity oscillator power supply. It will supply 34 kilovolts at 15 megawatts at a pulse rate of 4 per second. It will be capable of testing tubes at plate voltages up to 34 kilovolts. Hildebrand said that the bidding date for the injector power supply for Iivermore had to be extended about 10 days due to delays in mail delivery in the east due to resent serere storms in that area. These bids are now due in on December 11.

Panofsky said that the wide aperture calculations look rather goode A model test has been conducted of the first 4 drift tubes of Mark I using an input

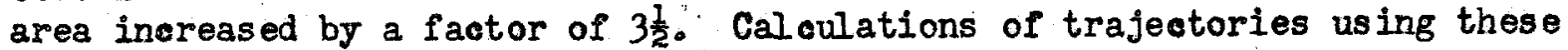
larger apertures is now beginning. 